\title{
Laboreal
}

Volume 8 No2 | 2012

A antropotecnologia, ferramenta ou engodo?

\section{Introducción al texto "La antropotecnología, ¿herramienta o trampa ?" de Alain Wisner}

Introdução ao texto "A antropotecnologia, ferramenta ou engodo ?" de Alain

Wisner

Introduction au texte "L'anthropotechnologie, outil ou leurre? » de Alain

Wisner

Introduction to the text of Alain Wisner "Anthropotechnology, tool or bait ?"

Leda Leal Ferreira

\section{OpenEdition}

Journals

Edición electrónica

URL: http://journals.openedition.org/laboreal/6508

DOI: $10.4000 /$ laboreal. 6508

ISSN: 1646-5237

Editor

Universidade do Porto

Referencia electrónica

Leda Leal Ferreira, «Introducción al texto "La antropotecnología, ¿herramienta o trampa ?" de Alain Wisner », Laboreal [En línea], Volume 8 №2 | 2012, Publicado el 01 diciembre 2012, consultado el 24 septiembre 2020. URL : http://journals.openedition.org/laboreal/6508; DOI : https://doi.org/10.4000/ laboreal.6508

Este documento fue generado automáticamente el 24 septiembre 2020

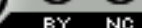

Laboreal está licenciado com uma Licença Creative Commons - Atribuição-NãoComercial 4.0 Internacional. 


\title{
Introducción al texto “La
} antropotecnología, ¿herramienta o trampa?" de Alain Wisner

\author{
Introdução ao texto "A antropotecnologia, ferramenta ou engodo?" de Alain
}

Wisner

Introduction au texte "L'anthropotechnologie, outil ou leurre? » de Alain

Wisner

Introduction to the text of Alain Wisner "Anthropotechnology, tool or bait ?"

Leda Leal Ferreira

\section{REFERENCIA}

Artigo original : Wisner, A. (1984). L'anthropotechnologie, outil ou leurre?

Technologies, Idéologies, Pratiques, 5, 28-59.

1 Es siempre un placer hablar o escribir sobre el profesor Alain Wisner. Ya tuve oportunidad de hacerlo en algunas ocasiones (Ferreira, 2004a e b; Ferreira \& Foret, 2006) y cada una de las mismas significó un momento para recordarlo con nostalgia. Por lo tanto, recibí con satisfacción la invitación de la revista Laboreal para expresar mi opinión sobre el texto Anthropotechnologie: outil ou leurre? de Wisner, publicado hace casi treinta años. En realidad, ya conocía este texto : el número cero, de 1999, de la revista Ação ergonômica, de la Asociación Brasileña de Ergonomía, ya lo había publicado con el título Antropotecnologia: ferramenta ou engodo? Junto a otros nueve textos, rindiendo un homenaje al profesor por su gran contribución al desarrollo de la ergonomía en Brasil.

2 El texto es muy didáctico, poniendo de manifiesto una de las principales características de Wisner : era, ante todo, un profesor preocupado por el aprendizaje de sus alumnos. Comienza preconizando que a las ciencias de la naturaleza, que se encuentran en la 
base de la ergonomía, se suman las ciencias sociales, cuando el problema al que se hace frente es mejorar la transferencia de tecnología desde el punto de vista de los trabajadores y de los países compradores. Éste sería el propósito de la antropotecnología. Acto seguido, describe las diversas modalidades de transferencia de tecnología, destacando el "extraordinario poder político de las empresas multinacionales en la vida de las naciones"; habla de las críticas procedentes de tres campos (de los "liberales", los "culturalistas" y los "marxistas") que recibe el enfoque antropotecnológico y propone una metodología para la antropotecnología, basada en el análisis del trabajo (al igual que en la ergonomía). Finalmente, responde positivamente a dos cuestiones que él mismo se plantea: la de la viabilidad y la utilidad de esta antropotecnología, que considera una nueva "práctica social".

3 A partir de esta relectura y sin ninguna pretensión de exhaustividad, propongo desarrollar algunas ideas, destacando tres puntos.

4 El primero se refiere al vocabulario empleado, los términos utilizados y los no utilizados. Es un alivio leer un texto que trata sobre el trabajo en el contexto de las relaciones comerciales, regionales o internacionales, sin tener que escuchar los términos "mundo globalizado", "globalización", "competitividad", "sostenibilidad", "gobernabilidad", "gestión", "estrategia competitiva", "innovación", etc. (por no hablar de "benchmarking", "empowerment", "management"...) que contaminan nueve de cada diez publicaciones más recientes. Creo que provocan confusión en las nuevas generaciones que ignoran que estos términos son un modismo de origen neoliberal y que, como ya apuntaron Bourdieu y Wacquant (2000), forman parte de una especie de nueva lengua, una "novlangue" vaga, basada en eufemismos, que trata de confundirnos. En el texto de Wisner encontramos términos que no existen prácticamente en los textos actuales : ya casi no se habla de "países en vías de desarrollo" (ni, como decía Wisner, "países en vías de desarrollo industrial" para destacar que su pobreza no era cultural sino económica). Ahora tenemos los "países emergentes". Del mismo modo, hoy ya no existen los países socialistas a los que Wisner se refería y, así, el término "tercer mundo" pierde un poco su sentido.

5 Todo ello no quiere decir que el texto no sea actual, al contrario. Las cuestiones planteadas por Wisner son en la actualidad aún más pertinentes por el simple hecho de que en los últimos años, la transferencia de tecnología ha ampliado sus modalidades y ha crecido en el mundo y, de esta forma, también han aumentado los problemas de falta de adaptación a los que tienen que enfrentarse los trabajadores. Lo que no ha aumentado es la preocupación frente a estos problemas. Las "enfermedades del desarrollo", es decir, diversas afecciones que aparecen o aumentan cuando se produce transferencia de tecnología, que preocupaban a Wisner, no forman parte en la actualidad de las agendas científicas en prácticamente ningún país. Se ignoran igualmente, o aún más, las "enfermedades olvidadas", que afectan a las poblaciones más pobres del mundo.

6 El segundo comentario se refiere al término antropotecnología. La antropotecnología en sí es un neologismo y puede querer decir varias cosas diferentes. Por ejemplo, fue éste el nombre que dos artistas brasileños emplearon en una exposición de cuadros y esculturas al que dieron el nombre de "antropotecnología, un análisis del ser humano desde el punto de vista de la tecnología". La antropotecnología es también una palabra empleada por el filósofo alemán Sloterdijk (2000), que trata de las cuestiones planteadas por el progreso de la ingeniería genérica y la biotecnología y el surgimiento 
de la tecnología de fabricación de seres humanos. Al menos en estos dos casos, la preocupación por los problemas vinculados a la transferencia de tecnología, que era la de Wisner, se aleja de la preocupación de las personas citadas.

No sé por qué Wisner lo eligió para designar el conjunto de sus interrogantes respecto a la transferencia de tecnología, principalmente de países desarrollados a países "en vías de desarrollo industrial", explicitados en el marco de varios estudios ergonómicos de varios de sus alumnos extranjeros en el Laboratorio de Ergonomía del CNAM, que dirigía en París. Lo que le preocupaba era cómo lograr que esta transferencia resultase satisfactoria para los trabajadores y los países compradores. Y desde hacía mucho, tal y como relata en su libro Quand voyagent les usines (Wisner, 1985). Desde la década de los 60 del siglo pasado, cuando fue invitado a impartir clases de ergonomía fuera de Francia (en Grecia, Argelia, México) y a continuación con la llegada de estudiantes extranjeros a su laboratorio, Wisner percibía que el arsenal teórico y práctico de ergonomía que se practicaba a la sazón resultaba insuficiente para comprender y resolver los problemas planteados en otras realidades diferentes a la francesa de aquella época.

8 La transferencia de tecnología que interesaba a Wisner, por lo tanto, no era la transferencia de conocimientos entre universidades y empresas. En realidad, Wisner se refería a una operación de compra y venta de tecnología, como dice Vargas, antiguo ministro de Ciencia y Tecnología en Brasil: "no es adecuado de hecho hablar genéricamente de "transferencia de tecnología. Se trata sobre todo de una operación de compra y venta, un comercio explícito o implícito" (Vargas, 1997). Para Wisner, "el problema de transferencia de tecnología representaba el punto crítico, el principal desafío del comercio internacional y el futuro de las condiciones de trabajo en los países en vías de desarrollo industrial" (Wisner, 1985, p. 49, traducción libre).

9 De cualquier forma, me parece claro que, a través de esta elección, estimó que el término ergonomía no daba cuenta de estas experiencias de transferencia de tecnología entre empresas. Tal vez porque consideraba que las disciplinas que se hallaban en la base de la ergonomía - sobre el ser humano individual- no eran suficientes para dar cuenta de los problemas colectivos - políticos, sociales, económicos e ideológicossuscitados por la transferencia de tecnología. Afirmaba lo siguiente :

"La ergonomía se basa en las ciencias del ser humano individual -la antropometría, la fisiología, la psicología cognitiva y, hasta cierto punto, un poco de microsociología. La antropotecnología plantea otra cuestión: la adaptación no del trabajo al ser humano, sino de la tecnología a los pueblos a los que se dirige, al comprador..." (Ferreira y Foret, 2006, p. 13, traducción libre).

10 Actualmente, el término antropotecnología se utiliza de un modo diferente del propuesto por Wisner. Para Mario Vidal, profesor de ergonomía en Río de Janeiro y uno de los primeros discípulos brasileños del profesor en París, responsable en gran medida de la difusión de la obra del maestro en Brasil (Wisner, 2004), la antropotecnología puede considerarse una "prolongación de la ergonomía" o una "tendencia de la ergonomía” (Vidal, 1994).

11 Ya François Daniellou, también profesor de ergonomía en Francia y asimismo discípulo de Wisner considera que : 
"el enfoque amplio de los factores determinantes de las situaciones de trabajo que Wisner preconizó con relación a la transferencia de tecnología se encuentra en la actualidad ampliamente difundido en la práctica de la ergonomía, exista o no transferencia de tecnología : la reflexión sobre los efectos de la historia, la geografía, los factores determinantes económicos, demográficos, culturales, etc. forman hoy parte de la vida cotidiana de numerosos ergonomistas. Actuar sobre la organización del trabajo es igualmente un objetivo de la acción ergonómica, actualmente muy difundido [...]. Existe ciertamente una diferencia de escala entre una intervención ergonómica en una cooperativa de Périgord y una transferencia de fábrica en África : pero no creemos que exista una diferencia de naturaleza" (Daniellou, 2006, p. 34, traducción libre).

12 No sé si Wisner estaría de acuerdo con estas interpretaciones, pero me temo que no. Por mi parte, pienso que si bien es cierto que algunos ergonomistas poseen "un enfoque amplio", éstos constituyen una minoría. La ergonomía que se aplica y difunde en cada país y en el mundo sigue siendo predominantemente una técnica que se restringe a una serie de recomendaciones impuestas a los trabajadores sobre sus posturas o gestos y a recomendaciones sobre formas y dimensiones de algunas máquinas, muebles o equipos. Lamentablemente, está más cerca de Frederick Taylor que de Alain Wisner.

El tercer y último punto que desearía comentar es la preocupación por el trabajo humano. Lo que caracteriza y diferencia el trabajo de Wisner, tanto en materia de ergonomía como de antropotecnología, es su preocupación por el trabajo humano. Se trata de una preocupación política que siempre lo guió en su práctica científica y su práctica social. Él mismo nos explicaba que, tanto en el enfoque ergonómico como en el antropotecnológico, la base es siempre el análisis del trabajo, realizado donde las personas trabajan o en los despachos donde permanecen sus superiores. Él se sublevaba contra el desconocimiento por parte de los diseñadores de máquinas o equipamientos acerca del trabajo realizado por los trabajadores. Debido a su desconocimiento de este trabajo o a su idea puramente abstracta y fuera de contexto del mismo, los "diseñadores" creaban aberraciones que solo dificultaban el trabajo y perjudicaban a los trabajadores. Podríamos pensar que el ejemplo que nos ofrecía, de la prohibición realizada a un responsable de la construcción de una máquina que provocaba accidentes de ir a la fábrica a ver cómo se estaba utilizando esta máquina era cosa del pasado, ya que este ejemplo sucedió en la década de los 60 del siglo pasado en la fábrica de Renault, en Francia (Ferreira \& Foret, 2006). Lamentablemente, no es este el caso. Las empresas siguen dificultando el acceso de técnicos a los lugares donde trabajan los operarios, tal y como demostró, por ejemplo, Inoue (2012) respecto a la prohibición de técnicos de seguridad en el trabajo de efectuar inspecciones en la planta de fabricación en algunas empresas metalúrgicas del Estado de São Paulo, el más rico de Brasil. Y el horror al trabajo de campo, al análisis del trabajo real, que impresionaba a Wisner, sigue predominando entre los responsables de las condiciones de trabajo en las empresas o en los gobiernos.

Situar el trabajo en el centro de las preocupaciones llevó a Wisner a preocuparse de la inteligencia. En primer lugar, de los operarios y trabajadores. Afirmaba lo siguiente : un ser humano no puede hacer nada, sentir nada sin pensar y, por lo tanto, un trabajador nunca es solo un ejecutante. Las implicaciones de este pensamiento están lejos de haberse agotado. A continuación, la inteligencia de los pueblos: nunca se permitió dictar normas a los dirigentes de empresas o gobiernos en los países a los que se le 
invitaba, sobre lo que sería mejor hacer. Aunque conociese la realidad de lo que ocurría en las empresas de varios países, en ocasiones mejor que algunos nativos, siempre fue consciente de los límites de cualquier intelectual cuando habla sobre realidades que no son las suyas, de historias que desconoce. Para Wisner, el "one best way" taylorista no existía.

Por mi parte, espero que estas preocupaciones de Wisner por el bienestar de los trabajadores y las naciones, por la "utilización de conocimientos técnicos sobre el ser humano relacionados con la vida industrial y técnica" tengan un futuro prometedor, inmediato o más tardío, bajo el nombre de la antropotecnología o bajo cualquier otro.

\section{BIBLIOGRAFÍA}

Bourdieu, P. \& Wacquant, L. (2000). La nouvelle vulgate planétaire. Le monde diplomatique, mai, 6-7. Daniellou, F. (2006). “Je me demanderais ce que la société attend de nous...”. À propos des positions epistémologiques d'Alain Wisner. Travailler, 15, 23-38.

Ferreira, L. L., \& Foret, J. (2006). Un entretien avec Wisner au Brésil. Travailler, 15,11-21.

Ferreira, L. L. (2004a). Sobre a "impostura do conceito de trabalho manual". Uma leitura da obra do Professor Alain Wisner. In Laerte Sznelwar e Fausto L. Mascia (Orgs.), Jornada de Ergonomia da Escola Politécnica de Universidade de São Paulo. DVD.

Ferreira, L. L. (2004b). Les trois leçons du Professeur Wisner. In Jacques Duraffourg et Bernard Vuillon (Dirs.), Alain Wisner et les tâches du présent. La bataille du travail réel (pp. 33-41). Toulouse : Octarès Éditions.

Inoue, K.S.Y. (2012). A atividade dos técnicos de segurança do trabalho em empresas metalúrgicas de Osasco/SP e região. Dissertação de mestrado. São Paulo : Faculdade de Saúde Pública da Universidade de São Paulo.

Sloterdijk, P. (2000). Regras para o parque humano. São Paulo : Editora Estação Liberdade.

Vargas, J.I. (1997). Mecanismos de transferência de tecnologia para países do terceiro mundo. Texto disponible en www.iea.usp.br/artigos. (acceso el 20/08/2012).

Vidal, M. C. (1994). Os paradigmas em ergonomia : uma epistemologia da insatisfação ou uma disciplina para a ação ? Texto disponible en http://www.ergonomianotrabalho.com.br/artigos/ Ergonomia_contemporanea.pdf (acceso el 30/08/2012).

Wisner, A. (1985). Quand voyagent les usines. Essai d'anthropotechnologie. Paris : Éditions Syros. Wisner, A. (1999). Antropotecnologia : ferramenta ou engodo. Ação Ergonômica, 1, (0), 7-35. Wisner, A. (2004). Textos escolhidos de Antropotecnologia. (Carvão, J.M.B. e Nascimento, A., Trad.). Org. Mario Cesar Vidal e José Mario Carvão. Rio de Janeiro : Editora Virtual Científica. 


\section{AUTOR}

\section{LEDA LEAL FERREIRA}

Antigua alumna de Alain Wisner y investigadora jubilada de la Fundacentro, Brasil ledalefe@gmail.com 